\title{
THEORETICAL INVESTIGATION ON THE NITROGEN-RICH ENERGETIC COMPOUND 5-NITRO-2-NITRATOMETHYL-1,2,3,4-TETRAZOLE
}

\author{
X.-Y. Gong ${ }^{1}$, X.-H. Li ${ }^{1,2}$, R.-Z. Zhang ${ }^{1}$ \\ ${ }^{1}$ College of Physics and Engineering, Henan University of Science and Technology, Luoyang, P.R. China \\ E-mail: lorna639@126.com \\ ${ }^{2}$ Luoyang Key Laboratory of Photoelectric Functional Materials, Henan University of Science and Technology, \\ Luoyang, China
}

\begin{abstract}
Based on the full optimized molecular geometric structures at the B3LYP/cc-pVTZ level, a new designed compound 5-nitro-2-nitratomethyl-1,2,3,4-tetrazole is investigated in order to look for high energy density compounds (HEDCs). The IR spectrum, the heat of formation (HOF), and frontier molecular orbitals are predicted. The detonation velocity and pressure are evaluated using Kamlet-Jacobs equations based on the theoretical density and condensed HOF. The bond dissociation energies (BDEs) and bond orders for the weakest bonds are analyzed to investigate the thermal stability of the title compound. The results show that the $\mathrm{O}_{1}-\mathrm{N}_{6}$ bond is the trigger bond. The crystal structure obtained by molecular mechanics belongs to the $P n a 2_{1}$ space group with lattice parameters $Z=4, a=13.7565 \AA, b=12.4737 \AA$, $c=4.3445 \AA$.
\end{abstract}

\section{DOI: $10.15372 / J S C 20150504$}

Ke y wor d s: density functional theory, detonation performance, bond dissociation energy, 5-nitro-2-nitratomethyl-1,2,3, 4-tetrazole, frontier molecular orbital.

\section{INTRODUCTION}

The design of nitrogen-rich energetic compounds and highly energetic materials for possible military application has been focused because of their high positive heats of formation (the number of nitrogen atoms linked together is directly proportional to the performance of the compound) $[1,2]$. Tetrazoles are typical high-nitrogen compounds with a high nitrogen content $(80 \%)$, possess a high positive heat of formation (HOF), and the tetrazole ring system is a powerful building block for highenergy compounds. Recently, the tetrazole compounds have found wide application in agriculture, medicine, biology, etc [3]. There is also a number of works investigating the potential of tetrazoles and their metal salts for their use as explosives [3-6].

From the energetic material point of view, the most desirable properties are a high positive HOF, a higher value of density etc. Nitrogen-rich heterocyclic compounds are considered to be suitable candidates for the high energetic density materials (HEDM) due to the inherent high density and the high positive HOF when compared to their carbon analogues. The inherent properties of these species can be tailor-made for suitable energetic application by replacing explosophoric groups, such as azides, nitro etc., by these azoles [ 7 ].

In addition, a high oxygen balance $(\mathrm{OB})$ is required for a compound to be a high-performing energetic. The oxygen balance is an expression used to indicate the degree to which an explosive can be oxidized and is easily calculated by the equation

(C) Gong X.-Y., Li X.-H., Zhang R.-Z., 2015 
Fig. 1. Molecular frameworks of the energetic tetrazole derivative

$$
\mathrm{OB}_{100}=\frac{n_{\mathrm{O}}-\left(0.5 * n_{\mathrm{H}}+2 n_{\mathrm{C}}\right)}{M} \times 16 \times 100,
$$

where $n_{\mathrm{O}}, n_{\mathrm{H}}$, and $n_{\mathrm{C}}$ represent the numbers of $\mathrm{O}, \mathrm{H}$, and $\mathrm{C}$ atoms respectively; $M$ is the molecular weight.

Researches show that the combination of high-nitrogen heterocycles with different oxygen-containing groups (such as the nitro group, $\mathrm{N}$-oxidation, etc.) is an effective method to improve the properties of tetrazole energetic compounds, especially in the aspects of enhancing the oxygen balance and increasing density [ 8-11].

Recently, the chemistry of neutral 5-nitrotetrazole derivatives has been the subject of systematic investigations [ 12,13$]$. It is a pressing need to incorporate more oxygen atoms into the tetrazole derivatives. Nitrate esters are one of the oldest classes of energetic materials which display an easy synthesis, a high oxygen content, and good combustion characteristics. The introduction of nitrate ester groups into the tetrazole ring may increase the number of oxygen atoms and push the limits of wellexplored tetrazole chemistry into a new, unexplored, dimension. Two-substituted 5-nitrotetrazoles, especially those with oxygen-containing group substituents, have a good oxygen balance and a high density $[14,15]$.

Thomas first synthesized 5-nitro-2-nitratomethyl-1,2,3,4-tetrazole [16] (Fig. 1), and the improved synthesis and characterization of the title compound together with a single crystal X-ray structure determination was performed by $\mathrm{Li}$ et al. [17]. Considering the importance of the compound as the energetic material, 5-nitro-2-nitratomethyl-1,2,3,4-tetrazole was first systematically studied by density functional theory (DFT). Its structural and energetic properties, such as thermodynamic properties, crystal density, detonation performance, frontier molecular orbitals, and thermal stability have been studied. These results provide useful information for the molecular design of novel HEDMs.

\section{COMPUTATIONAL METHODS AND DETAILS}

The DFT-B3LYP method has emerged as a very reliable theoretical method [18-20] because it could give reasonable energies, molecular structures, and infrared vibrational frequencies. In this paper, the B3LYP/cc-pVTZ method in the Gaussian 03 package [21] was used to optimize the molecular geometries of the title compound. The optimized structure was characterized to be the local energy minimum on the potential energy surface by the vibrational analysis. The NBO calculations were performed using the NBO 3.1 program as implemented in the Gaussian 03 package [21] at the B3LYP/cc-pVTZ level.

Previous studies show that the DFT-B3LYP method has been successfully used to predict HOFs of many organic systems via isodesmic reactions [22-25]. In addition, the energies calculated with the cc-pVTZ basis set are more reliable than those obtained with other basis sets. Thus, in many works the cc-pVTZ basis set has been used to obtain the related parameters [26-29].

The computational details of isodesmic reaction processes are given in the previous studies [ 30 ]. Since the condensed phase for most energetic compounds is solid, the calculation of detonation properties requires a solid phase HOF $\left(\Delta H_{f \text {, solid }}\right)$. According to Hess's law of constant heat summation [ 31 ], the gas-phase $\operatorname{HOF}\left(\Delta H_{f, \text { gas }}\right)$ and the heat of sublimation $\left(\Delta H_{f, \text { sub }}\right)$ can be used to evaluate their solid phase HOF

$$
\Delta H_{f, \text { solid }}=\Delta H_{f, \text { gas }}-\Delta H_{f, \text { sub }} .
$$

Politzer et al. [32, 33] found that the heats of sublimation can correlate well with the molecular surface area and the electrostatic interaction index $v \delta_{\text {tot }}^{2}$ of energetic compounds. The empirical expression of the approach is as follows:

$$
\Delta H_{\text {sub }}=a A^{2}+b \sqrt{v \delta_{\text {tot }}^{2}}+c,
$$

where $A$ is the surface area of the 0.001 electrons $/$ bohr ${ }^{3}$ isosurface of the electron density of the mole- 
cule, $v$ describes the degree of balance between the positive and negative potentials on the isosurface, and $\delta_{\text {tot }}^{2}$ is a measure of variability of the electrostatic potential on the molecular surface. Coefficients $a, b$, and $c$ were determined by Byrd and Rice [34 ]. Descriptors $A, v$, and $\delta_{\text {tot }}^{2}$ were calculated using the computational procedures proposed by $\mathrm{Lu}[35$ ].

For the title compounds, the explosive reaction is designed in terms of the maximum exothermal principle. For the explosives with $\mathrm{CHNO}$ elements, detonation velocities and pressures can be calculated by the Kamlet—Jacobs equation [36, 37]

$$
\begin{gathered}
D=1.01 \times \Phi^{0.5}(1.0+1.3 \rho), \\
\Phi=N \bar{M}^{0.5} Q^{0.5}, \\
P=1.558 \times \Phi \rho^{2},
\end{gathered}
$$

where each term in Eqs. (4) and (5) is defined as follows: $P$ is the detonation pressure (GPa); $D$ is the detonation velocity $(\mathrm{km} / \mathrm{s}) ; \rho$ is the density of the explosive $\left(\mathrm{g} / \mathrm{cm}^{3}\right)$; $\Phi$ is the characteristic value of explosives; $N$ is the number of gas moles produced per gram of explosives; $\bar{M}$ is the average molar weight of detonation products; and $Q$ is the estimated heat of detonation $(\mathrm{cal} / \mathrm{g})$. The density of each compound was obtained from the molar weight $(M)$ divided by the average molar volume $(V)$ which was obtained from the arithmetic average value of 100 single-point molar volumes, defined as the volume of the 0.001 electron Bohr $^{-3}$ electron density envelope and computed by the Monte Carlo integration implemented in the Gaussian 03 program based on the optimized geometrical structure.

The possible polymorphs and crystal structures of the title compound were predicted by rigorous molecular packing calculations using a polymorph module of Material Studio [38 ] since the highenergy compounds are usually in condensed phases, especially in the solid state. The COMPASS force-field is used to search for the possible molecular packing among the most probable seven space groups $\left(P 2_{1} / c, P-1, P 22_{1} 2_{1} 2_{1} P b c a, C 2 / c, P 2_{1}\right.$, and $\left.P n a 2_{1}\right)[39-42]$.

The bond dissociation energy (BDE) is used to evaluate the pyrolysis mechanism and thermal stability. BDE is defined as the difference between the energies of the parent molecule and the corresponding radicals in the unimolecular bond dissociation [ 43 ].

\section{RESULTS AND DISCUSSION}

Infrared spectrum. The IR spectrum is one of the basic properties of a compound. It is often used to analyze or identify substances and has a direct relation to the thermodynamic properties. Therefore, it is of great significance to calculate the IR and thermodynamic properties of the title compound by a theoretical method. Here, the vibrational frequencies were calculated at the DFT B3LYP/cc-pVTZ level. Fig. 2 presents the simulated IR spectrum based on the scaled harmonic vibrational frequencies.

Obviously, there are five main characteristic regions. The modes at $3129-3213 \mathrm{~cm}^{-1}$ are associated with the $\mathrm{C}-\mathrm{H}$ stretch. In this region, the strongest characteristic peak is at $3199 \mathrm{~cm}^{-1}$. The modes at $1637-1668 \mathrm{~cm}^{-1}$ are associated with the $\mathrm{N}=\mathrm{O}$ asymmetric stretch of nitro groups and the strong characteristic peak is at $1668 \mathrm{~cm}^{-1}$, which is in good agreement with the experimental $\mathrm{N}=\mathrm{O}$

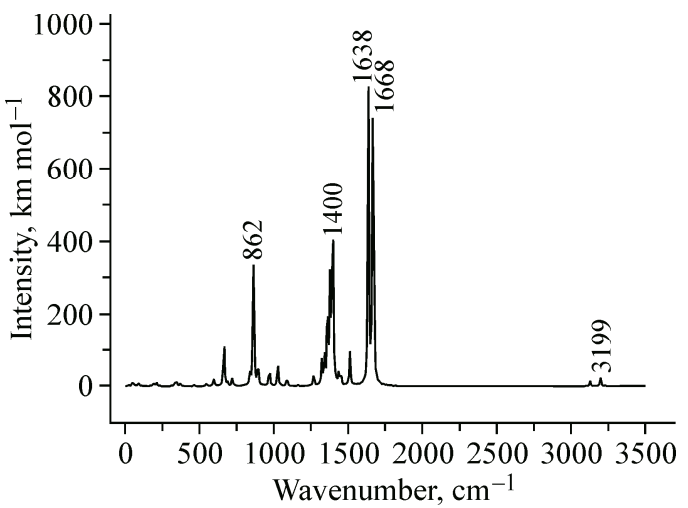
stretching vibration at $1676 \mathrm{~cm}^{-1}[17]$. At $1638 \mathrm{~cm}^{-1}$ there is a sharp $\mathrm{C}-\mathrm{NO}_{2}$ peak that corresponds to the experimental value of $1562 \mathrm{~cm}^{-1}$ [17]. These deviations between the theoretical and experimental vibrations are generally acceptable in theoretical calculations [44]. The modes at $1361-1437 \mathrm{~cm}^{-1}$ are mainly associated with the $\mathrm{C}-\mathrm{N}$ stretch and the strongest peak is at $1400 \mathrm{~cm}^{-1}$. The modes at $839-892 \mathrm{~cm}^{-1}$ are composed of $\mathrm{NO}_{2}$ wagging and $\mathrm{CNO}$ wagging and the strongest

Fig. 2. Simulated IR spectrum of the title compound 
characteristic peak is at $862 \mathrm{~cm}^{-1}$. The weak peaks less than $800 \mathrm{~cm}^{-1}$ are mainly caused by the deformation of the ring skeleton and the bending vibration of the $\mathrm{C}-\mathrm{H}$ bond.

Heat of formation. The heat of formation is taken to be indicative of the "energy content" of a HEDM, which can be used to estimate the amount of energy released or absorbed in a chemical reaction. The atomization reaction or isodesmic reaction method can be used to obtain the standard HOF at $298.15 \mathrm{~K}$. In this paper the isodesmic reaction method is employed. The isodesmic reaction, where the numbers of bonds and bond types are preserved on both sides of the reaction, often leads to cancellation of systematic errors resulting from the bond environments, spin contamination, basis set superposition, and other nonrandom factors [45]. The accuracy of the HOF obtained theoretically is conditioned by the reliability of the HOF of the reference compounds.

The HOF for the title compound can be derived from the following isodesmic reaction:

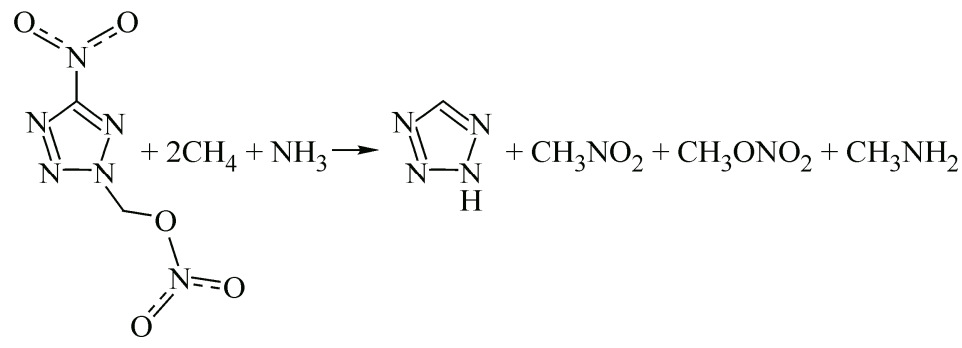

Table 1 lists the total energies, experimental HOFs, and zero-point energies at the B3LYP/ccpVTZ level for the compounds involved in the isodesmic reaction. In order to have a comparison, the HOFs of 1,3,5-trinitro-1,3,5-triazacyclohexane (RDX) and 1,3,5,7-tetranitro-1,3,5,7-tetrazocane (HMX) were also listed in Table 1. The HOFs of HMX and RDX were obtained through the isodesmic reaction: $\mathrm{X}-\left(\mathrm{NO}_{2}\right)_{n}+n \mathrm{CH}_{4} \rightarrow \mathrm{X}-\mathrm{H}+n \mathrm{CH}_{3} \mathrm{NO}_{2}(4 \leq n \leq 8)$, where the HOF of the $\mathrm{X}-\mathrm{H}$ molecule was found out for the atomization reaction by $\mathrm{G} 2$ theory.

It is noted that the HOF of the title compound is positive and larger than those of RDX and HMX, which benefits the heat release during the detonation.

The solid-phase HOF $\left(\Delta H_{f, \text { solid }}\right)$ is an important property to predict the detonation properties of the energetic materials. Using the method of Politzer et al. [32, 33 ], the $\Delta H_{f \text {, sub }}$, the descriptors $A, v, \delta_{\text {tot }}^{2}$, and $\Delta H_{f \text {, solid }}$ were all listed in Table 2. Density is one of the critical factors that determine the energetic properties of compounds. According to the Kamlet_Jacobs equation [36,37], the density greatly affects the detonation performance. The detonation pressure is dependent on the square of the density, while the detonation velocity is proportional to the density. The density of the title compound is also included in Table 2. For comparison, the experimental densities and HOFs of HMX and RDX are also

T a b l e 1

Calculated total energy $\left(E_{0}\right)$, zero-point energy (ZPE), and experimental heats of formation of the reference compounds at the $\mathrm{B} 3 \mathrm{LYP} / \mathrm{cc}-\mathrm{pVTZ}$ level $\left(E_{0}\right.$ and $\mathrm{ZPE}$ are in a.u., $\mathrm{HOF}$ is in $\left.\mathrm{kJ} / \mathrm{mol}\right)$

\begin{tabular}{|c|c|c|c|c|c|c|c|}
\hline Compounds & $E_{0}$ & ZPE & $\mathrm{HOF}$ & Compounds & $E_{0}$ & ZPE & HOF \\
\hline $\mathrm{CH}_{4}$ & -40.493635 & 0.044609 & $-74.8^{\mathrm{a}}$ & $\mathrm{CH}_{3} \mathrm{ONO}_{2}$ & -320.264996 & 0.05414 & $-123.02^{\mathrm{e}}$ \\
\hline $\mathrm{CH}_{3} \mathrm{NO}_{2}$ & -245.059742 & 0.049712 & $-80.7^{\mathrm{a}}$ & The title compound & -781.929157 & 0.084112 & 276.09 \\
\hline $\mathrm{NH}_{3}$ & -56.550465 & 0.03426 & $-45.9^{b}$ & RDX & -897.2732 & 0.143296 & $175.37^{\mathrm{f}}$ \\
\hline $\mathrm{CH}_{3} \mathrm{NH}_{2}$ & -95.836193 & 0.063781 & $-23.5^{\mathrm{c}}$ & HMX & $\mid-1196.3655$ & 0.192075 & $210.39^{f}$ \\
\hline 2H-1,2,3,4-tetrazole & -258.302005 & 0.047454 & $\left|318.2^{\mathrm{d}}\right|$ & & & & \\
\hline
\end{tabular}

${ }^{a}$ Data [46].

${ }^{\mathrm{b}}$ Data from NIST Chemistry WebBook.

${ }^{\mathrm{c}}$ Data from [ 47 ].
${ }^{\mathrm{d}}$ Data from [ 48 ].

${ }^{\mathrm{e}}$ Data from [ 49 ].

${ }^{\mathrm{f}}$ Data from [ 50 ]. 


\begin{tabular}{l|c|c|c|r|c|c}
\multicolumn{7}{c}{ Density, $A, v, \delta_{\text {tot }}^{2}, \Delta H_{f, \text { sub }}$, and $\Delta H_{f, \text { solid }}$ of the title compound } \\
\hline \multicolumn{1}{c|}{ Compound } & $A$ & $v$ & $\delta_{\text {tot }}^{2}$ & $\Delta H_{f, \text { sub }}$ & $\Delta H_{f, \text { solid }}$ & $\rho$ \\
\hline Title compound & 183.79 & 0.07545 & 306.85 & 83.28 & 192.81 & 1.91 \\
HMX & 254.63 & 0.1684 & 141.18 & 118.36 & $92.00(75.00)^{\mathrm{c}}$ & $1.89(1.90)^{\mathrm{b}}$ \\
RDX & 190.34 & 0.1805 & 171.17 & 91.16 & 84.21 & $1.78(1.82)^{\mathrm{b}}$
\end{tabular}

${ }^{\mathrm{a}}$ Unit: $\Delta H_{f \text {, sub }}(\mathrm{kJ} / \mathrm{mol}), \Delta H_{f \text {, solid }}(\mathrm{kJ} / \mathrm{mol}), \rho\left(\mathrm{g} / \mathrm{cm}^{3}\right)$.

${ }^{\mathrm{b}}$ Data in parentheses are the experimental values taken from [ 50, 51 ].

${ }^{\mathrm{c}}$ Data from [ 52 ].

listed in this table. It is noted that the density of the studied compound is $1.91 \mathrm{~g} / \mathrm{cm}^{3}$, which is higher than those of RDX and HMX.

Detonation properties. To find a new energetic material, it is essential to have its detonation velocity $(D)$ and pressure $(P)$ using the Kamlet-Jacobs equation [36, 37]. Based on the condensed HOFs and densities of the title compound, the detonation properties, including $Q, D$, and $P$, were estimated. Table 3 lists $D, P, Q$, and $\mathrm{OB}_{100}$ of the title compound. For a better comparison and evaluation of the detonation performance of the title compound, the experimental data [53 ] on RDX and HMX are also listed in Table 3. As is evident from Table 3, the calculated detonation properties of RDX and HMX agree well with the available experimental values [53 ]. Although the errors caused by the limitations of the calculation method make the predicted properties somewhat deviate from the experimental values, these computational results are still reliable.

Obviously, the detonation velocity and pressure of the title compound are all larger than those of RDX, but smaller than those of HMX. This shows that the title compound is a potential HEDM.

Electronic structure and thermal stability. A main concern for the energetic materials is whether molecules are thermally stable enough to be of practical interest. At present, the strength of the weakest bond is most widely used to index the relative sensitivity. The stronger the weakest bond, the more stable the energetic materials are. The stability of the energetic material is related to a certain extent to the strength of the weakest bond and this can be evaluated via the bond dissociation energy (BDE). The BDE can evaluate the strength of the bonding that is fundamental to understand the decomposition process of the energetic materials. Since there may be several bonds of the same kind in a molecule, the Wiberg bond indexes (WBIs) from NBO analysis were used to ascertain the weakest bond. A high WBI value indicates a stronger bond, whereas a low WBI value shows a weaker bond, so the bond with the smallest WBI among all bonds of the same type was considered. Table 4 lists some WBIs of the title compound.

$\mathrm{T}$ a b 1 e 3

$\mathrm{T}$ a b 1 e 4

Predicted detonation properties of the considered compounds $^{\text {a }}$

\begin{tabular}{|c|c|c|c|c|}
\hline Compound & $\mathrm{OB}_{100}^{\mathrm{b}}$ & $Q$ & $D$ & $P$ \\
\hline Title compound & 42.1 & 5794 & 9.03 & 37.4 \\
\hline $\mathrm{RDX}^{\mathrm{b}}$ & -21.6 & 6500 & $\begin{array}{c}8.98 \\
(8.75)\end{array}$ & $\begin{array}{c}35.13 \\
(34.00)\end{array}$ \\
\hline $\mathrm{HMX}^{\mathrm{b}}$ & -21.6 & 6700 & $\begin{array}{c}9.35 \\
(9.10)\end{array}$ & $\begin{array}{c}38.24 \\
(39.00)\end{array}$ \\
\hline
\end{tabular}

\begin{tabular}{|c|c|c|}
\hline Title compound & WBI & $\mathrm{BDE}$ \\
\hline $\mathrm{N}_{1}-\mathrm{N}_{2}$ & 1.2664 & - \\
\hline $\mathbf{N}_{2}-\mathbf{N}_{3}$ & 1.2481 & 118.2867 \\
\hline $\mathrm{N}_{3}-\mathrm{N}_{4}$ & 1.5467 & - \\
\hline $\mathrm{N}_{4}-\mathrm{C}_{1}$ & 1.3348 & 122.729 \\
\hline $\mathrm{C}_{1}-\mathrm{N}_{1}$ & 1.4836 & - \\
\hline $\mathrm{C}_{1}-\mathrm{N}_{5}$ & 0.8974 & 259.5018 \\
\hline $\mathrm{N}_{2}-\mathrm{C}_{2}$ & 0.9514 & - \\
\hline $\mathrm{C}_{2}-\mathrm{O}_{1}$ & 0.9013 & 251.14 \\
\hline $\mathrm{O}_{1}-\mathrm{N}_{6}$ & 0.8552 & 99.27 \\
\hline
\end{tabular}

\footnotetext{
${ }^{\mathrm{a}}$ Units: $\left.V, \mathrm{~cm}^{3} \cdot \mathrm{mol}^{-1}, Q, \mathrm{~J} \cdot \mathrm{g}^{-1}, D, \mathrm{~km} \cdot \mathrm{s}^{-1}\right), P, \mathrm{GPa}$.

${ }^{\mathrm{b}}$ Data for RDX and HMX are from [ 52 ].
} 
Unit cell parameters of the possible molecular packings of the title compound

\begin{tabular}{l|c|c|c|c|c|c|c}
\hline \multirow{2}{*}{ Parameters } & \multicolumn{7}{c}{ Space groups } \\
\cline { 2 - 7 } & $C 2 / c$ & $P 1$ & $P 2_{1} 2_{1} 2_{1}$ & $P 2_{1}$ & $P 2_{1} / c$ & $P n a 2_{1}$ & $P b c a$ \\
\hline$Z$ & 8 & 2 & 4 & 2 & 4 & 4 & 8 \\
$E, \mathrm{~kJ} \cdot \mathrm{mol}^{-1} \cdot \mathrm{cell}^{-1}$ & 4.40 & 7.24 & -5.14 & 0.56 & -5.07 & -18.29 & 4.16 \\
$\rho, \mathrm{g} / \mathrm{cm}^{-3}$ & 1.825 & 1.953 & 1.956 & 1.980 & 2.004 & 1.901 & 1.932 \\
$a, \AA$ & 36.459 & 5.107 & 11.700 & 10.599 & 8.398 & 13.757 & 14.011 \\
$b, \AA$ & 10.552 & 8.399 & 5.957 & 5.336 & 8.932 & 12.474 & 7.623 \\
$c, \AA$ & 8.481 & 8.143 & 9.376 & 5.593 & 9.611 & 4.345 & 13.677 \\
$\alpha, \mathrm{deg}$. & & 100.65 & & & & & \\
$\beta, \mathrm{deg}$. & 23.69 & 105.23 & 90.00 & 87.22 & 117.14 & 90.00 & 90.00 \\
$\gamma, \mathrm{deg}$. & & 73.46 & & & & &
\end{tabular}

In this paper, five possible initial steps, i.e. the cleavage of $\mathrm{C}-\mathrm{N}$ and $\mathrm{N}-\mathrm{N}$ bonds in the tetrazole skeleton and the $\mathrm{C}-\mathrm{N}, \mathrm{C}-\mathrm{O}$ and $\mathrm{O}-\mathrm{N}$ bonds in the side chain are considered. It is noted that $\mathrm{O}_{1}-\mathrm{N}_{6}, \mathrm{C}_{2}-\mathrm{O}_{1}$, and $\mathrm{C}_{1}-\mathrm{N}_{5}$ bonds in the side chain and $\mathrm{C}_{1}-\mathrm{N}_{4}$ and $\mathrm{N}_{2}-\mathrm{N}_{3}$ bonds in the tetrazole ring have smaller WBIs among the same kind of bonds. The corresponding BDEs are also calculated and listed in Table 4.

It is noted that the BDE of $\mathrm{O}_{1}-\mathrm{N}_{6}$ is $99.27 \mathrm{~kJ} / \mathrm{mol}^{-1}$, which is weaker than those of $\mathrm{C}_{1}-\mathrm{N}_{5}$, $\mathrm{C}_{1}-\mathrm{N}_{4}, \mathrm{C}_{2}-\mathrm{O}_{1}$, and $\mathrm{N}_{2}-\mathrm{N}_{3}$ bonds. This indicates that the $\mathrm{O}_{1}-\mathrm{N}_{6}$ bond breaks more easily and may be the trigger bond.

Molecular packing prediction and density. The crystal structure of the title compound is predicted by the COMPASS force field [ 54 ], which can produce the gas- and condensed-phase properties reliably for a broad range of systems [55]. Using the COMPASS force field, we can pack arrangements in all reasonable space groups to search for the low-lying minima on the lattice energy surface. The structure optimized by the B3LYP/cc-pVTZ method is considered as an input structure for the polymorph search. Table 5 lists the lattice parameters in all reasonable space groups.

It is noted from Table 5 that the energies range from $-18.29 \mathrm{~kJ} \cdot \mathrm{mol}^{-1} \cdot \operatorname{cell}^{-1}$ to $7.24 \mathrm{~kJ} \cdot \mathrm{mol}^{-1} \cdot \mathrm{cell}^{-1}$ and the structure with the Pna2 ${ }_{1}$ symmetry has the lowest energy. Therefore, the most possible space group of the title compound predicted by the COMPASS force field is the space group Pna2 $2_{1}$. The corresponding lattice parameters are $Z=4, a=13.757 \AA, b=12.474 \AA, c=4.345 \AA, \rho=1.901 \mathrm{~g} / \mathrm{cm}^{-3}$. Obviously, the density $\left(1.901 \mathrm{~g} / \mathrm{cm}^{-3}\right)$ obtained by the COMPASS force field is closer to the density $\left(1.91 \mathrm{~g} / \mathrm{cm}^{-3}\right)$ obtained by density functional method. Fig. 3 gives the molecular packing of the title compound in the space group Pna2 ${ }_{1}$.

\section{CONCLUSIONS}

In this paper, theoretical investigations have been performed on the energetic material 5-nitro-2nitratomethyl-1,2,3,4-tetrazole using the B3LYP/cc-pVTZ method. The IR spectrum, detonation properties, HOF, and the weakest bond were predicted. The results show that the title compound possesses a very high HOF, which is larger than that of HMX. The detonation velocity and pressure are also larger than those of RDX and smaller than those of HMX. The $\mathrm{O}_{1}-\mathrm{N}_{6}$ bond is predicted to be the trigger bond during pyrolysis, based on the results of the bond order and bond dissociation energy. In addition, the most

Fig. 3. Molecular packing of the title compound in the space

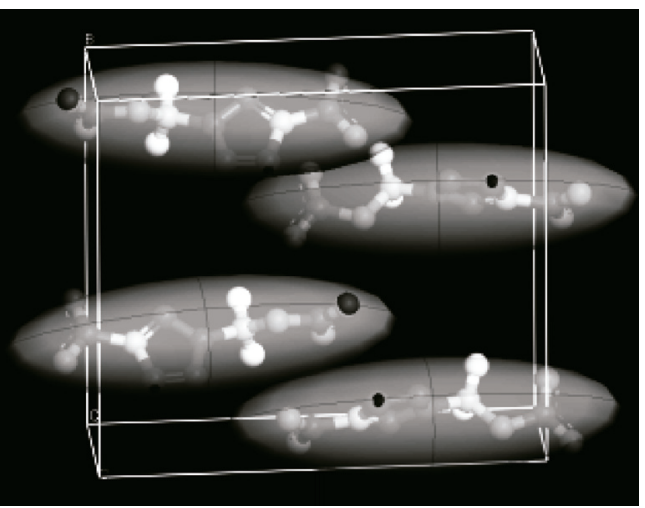
group $P n a 2_{1}$ 
possible space group of the title compound predicted by the COMPASS force field is Pna2 ${ }_{1}$. All calculation results indicate that the title compound is a potential candidate of HEDM.

We gratefully thank the National Natural Science Foundation of China (Grant U1304111), China Postdoctoral Science Foundation (No. 2013M531361) and Jiangsu Planned Projects for Postdoctoral Research Funds (No. 1201015B) for their support of this work.

\section{REFERENCES}

1. Chavez D.E., Hiskey M.A., Gilardi R.D. // Angew. Chem., Int. Ed. - 2000. - 112. - P. 1861 - 1863.

2. Hammerl A., Klapötke T.M., Nöth H., Warchhold M., Holl G., Kaiser M. // Inorg. Chem. - 2001. - 40. - P. $3570-3575$.

3. Katritzky A.R., Rees C.W. Comprehensive Heterocyclic Chemistry. - Elmsford-NY: Pergamon Press, 1984.

4. Spear R.J., Bentley J.R., Wolfson M.G. // Combust. Flame. - 1983. - 50. - P. 249 - 258.

5. Whelan D.J., Spear R.J., Read R.W. // Thermochim. Acta. - 1984. - 80. - P. 149 - 163.

6. Bates L.R. The potential of tetrazoles in initiating explosive systems / Proc. $13^{\text {th }}$ Symp. Explos. Pyrotech, Head Island, 1986.

7. Ostrovskii V.A., Pevzner M.S., Kofman T.P., Tselinskii I.V. // Targets Heterocycl. Syst. - 1999. - 3. - P. 467 526.

8. Harel T., Rozen S. // J. Org. Chem. - 2010. - 75. - P. 3141 - 3143.

9. Gao H.X., Shreeve J.M. // Chem. Rev. - 2011. - 111. - P. 7377 - 7436.

10. Bottaro J.C., Petrie M.A., Penwell P.E., Dodge A.L., Malhotra R., Nano/HEDM Technology: Late Stage Exploratory Effort; Report No. A 466714; SRI International: Menlo Park, CA, USA, 2003.

11. Klapötke T.M., Mayer P., SabatéC.M., Welch J.M., Wiegand N. // Inorg. Chem. - 2008. - 47. - P. 6014 6027.

12. Klapötke T.M., Sabaté C.M., Stierstorfer J. // New J. Chem. - 2009. - 33. - P. 136 - 147.

13. Semenov V.V., Shevelev S.A. // Mendeleev Comm. - 2010. - 20. - P. 332 - 334.

14. Semenov V.V., Shevelev S.A., Bruskin A.B., Kanishchev M.I., Baryshnikov A.T. // Russ. Chem. Bull. - 2009. - 58. - P. 2077 - 2096.

15. Vasiliev A.D., Astachov A.M., Golubtsova O.A., Pekhotin K.V., Rogozin M.V., Kruglyakova L.A., Stepanov R.S. // Acta Crystallogr. Sect. C Cryst. Struct. Commun. - 2001. - C57. - P. $1101-1102$.

16. Klapotke T.M., Sabate C.M., Rasp M. // J. Mater. Chem. - 2009. - 19. - P. 2240 - 2252.

17. Li Y.C., Liu W., Pang S.P. // Molecules. - 2012. - 17. - P. $5040-5049$.

18. Li X.H., Zhang R.Z., Zhang X.Z. // J. Hazard Mater. - 2010. - 183. - P. $622-631$.

19. Li X.H., Cheng Q.D., Zhang X.Z. // J. Energetic Mater. - 2010. - 28. - P. $251-272$.

20. Xu X.J., Xiao H.M., Ju X.H., Gong X.D., Zhu W.H. // J. Phys. Chem. A. - 2006. - 110. - P. 5929 - 5933.

21. Frisch M.J., Trucks G.W., Schlegel H.B., Scuseria G.E., Robb M.A., Cheeseman J.R., Gakrzewski Z.V., Montgomery J.A., Stratmann R.E., Burant J.C., Dapprich S., Millam J.M., Daniels A.D., Kudin K.N., Strain M.C., Farkas O., Tomasi J., Barone V., Cossi M., Cammi R., Mennucci B., Pomelli C., Adamo C., Clifford S., Ochterski J., Petersson G.A., Ayala P.Y., Cui Q., Morokuma K., Malick D.K., Rabuck A.D., Raghavachari K., Foresman J.B., Cioslowski J., Ortiz J.V., Baboul A.G., Stefanov B.B., Liu G., Liashenko A., Piskorz P., Komaromi I., Gomperts R., Martin R.L., Fox D.J., Keith T., Al-Laham M.A., Peng C.Y., Nanayakkara A., Gonzalez C., Challacombe M., Gill P.W., Johnson B., Chen W., Wong M.W., Andres J.L., Gonzalez C., Head2Gordon M., Replogle E.S., Pople J.A Gaussian 03, Revision B.02, Gaussian Inc., Pittsburgh, PA, 2003.

22. Selmi M., Tomasi J. // J. Phys. Chem. - 1995. - 99. - P. $5894-5898$.

23. Chen Z.X., Xiao J.M., Xiao H.M., Chiu Y.N. // J. Phys. Chem. A. - 1999. - 103. - P. 8062 - 8066.

24. Xiao H.M., Chen Z.X. The Modern Theory for Tetrazole Chemistry, 1st edn. - Beijing: Science Press, 2000.

25. Chen P.C., Chieh Y.C., Tzeng S.C. // J. Mol. Struct.: THEOCHEM. - 2003. - 634. - P. 215 - 224.

26. Ravi P. // J. Mol. Model. - 2013. - 19. - P. 4741 - 4751.

27. Bartoskova M., Friedl Z. // Cent. Eur. J. Energ. Mat.. - 2013. - 10. - P. 103 - 112.

28. Zhang J.-G., Zhang S.W., Li Q.S. // Chem. Phys. Let. - 2005. - 407. - P. $315-321$.

29. Kameron R.J., Gbenga A.O., Angela K.W. // J. Hazard. Mater. - 2011. - 186. - P. 583 - 589.

30. Li X.H., Zhang R.Z., Zhang X.Z. // J. Hazard. Mater. - 2010. - 183. - P. 622 - 631.

31. Atkins P.W. Physical chemistry. - Oxford: Oxford University Press, 1982.

32. Politzer P., Lane P., Murray J.S. // Cent. Eur. J. Energ. Mater. - 2011. - 8. - P. 39 - 52.

33. Politzer P., Murray J.S. // Cent. Eur. J. Energ. Mater. - 2011. - 8. - P. $209-220$.

34. Byrd E.F.C., Rice B.M. // J. Phys. Chem. A. - 2006. - 110. - P. $1005-1013$. 
35. Lu T., Chen F.W. // J. Comp. Chem. - 2012. - 33. - P. $580-592$.

36. Kamlet M.J., Jacobs S.J. // J. Chem. Phys. - 1968. - 48. - P. 23 - 25.

37. Zhang X.H., Yun Z.H. Explosive Chemistry. - Beijing: National Defense Industry Press, 1989.

38. Materials Studio 4.4. Accelrys, 2008.

39. Mighell A.D., Himes V.L., Rodgers J.R. // Acta Crystallogr. - 1983. - 39. - P. 737 - 742.

40. Wilson A.J.C. // Acta Crystallogr. A. - 1988. - 44. - P. 715 - 724.

41. Srinivasan R. // Acta Crystallogr. A. - 1992. - 48. - P. 917 - 918.

42. Baur W.H., Kassner D. // Acta Crystallogr. B. - 1992. - 48. - P. 356 - 369.

43. Benson S.W. Thermochemical Kinetics. - New York: Wiley Interscience, 1976.

44. Cook D.B. Hand book of Computational Quantum Chemistry. - New York: Oxford University Press, 1998.

45. Hehre W.J., Radom L., Schleyer P.V.R. Ab Initio Molecular Orbital Theory. - New York: Wiley, 1986.

46. Scott A.P., Radom L. // J. Phys. Chem. - 1996. - 100. - P. $16502-16513$.

47. Frenkel M., Kabo G.J., Marsh K.N., Roganov G.N., Wilhoit R.C. Thermodynamics of Organic Compounds in the Gas State; Thermodynamic Research Center: College Station, TX, 1994.

48. Pelly J.B., Naylor R.D., Kirby S.P. Thermochemical Data of Organic Compounds, 2nd ed. - London, New York: Chapman and Hall, 1986.

49. Rice B.M., Pai S.V. // Combust. Flame. - 1999. - 118. - P. 445 - 448.

50. Willer R.L. // Propellants, Explos., Pyrotech. - 1983. - 8. - P. 65 - 69.

51. Talawar M.B., Sivabalan R., Mukundan T., Muthurajan H., Sikder A.K., Gandhe B.R., Rao A.S. // J. Hazard. Mater. - 2009. - 161. - P. 589 - 607.

52. Meyer R., Köhler J., Homburg A. Explosives, $6^{\text {th }}$ ed. - Weinheim: Wiley-VCH, 2007.

53. Sasada Y. Molecular and Crystal Structures in Chemistry Handbook. 3rd ed. - Tokyo: The Chemical Society of Japan, Maruzen, 1984.

54. Sun H. // J. Phys. Chem. B. - 1998. - 102. - P. 7338 - 7364.

55. Хu X.J., Zhu W.H., Xiao H.M. // J. Phys. Chem. B. - 2007. - 111. - P. 2090 - 2097. 